\title{
Expanding the pool of deceased organ donors: the ICU and beyond
}

\author{
Alexander Manara ${ }^{1}$, Francesco Procaccio ${ }^{2}$ and Beatriz Domínguez-Gil ${ }^{3^{*}}$ (1)
}

(c) 2019 Springer-Verlag GmbH Germany, part of Springer Nature

Organ transplantation is a therapy that benefits thousands of patients every year. Its expansion is, however, limited by our chronic inability to meet the transplantation needs of patients. The World Health Organization (WHO) has called governments to progress towards self-sufficiency in transplantation, primarily by maximizing donation from the deceased. This requires adopting a whole hospital approach to identify areas of current medical practice that lead to the loss of donation potential, particularly in the management of patients with severe brain injuries who die despite initial active treatment, those with devastating brain injury (DBI) - defined as any neurological condition perceived as an immediate threat to life or incompatible with good functional recovery and where withdrawal or withholding of life-sustaining therapy is being considered-and those after unsuccessful cardiopulmonary resuscitation.

The primary duty of physicians is to preserve a patient's life and to base their decisions not only on medical considerations but also on the values and preferences of their patients. When it is recognized that further active treatment is no longer in the best interests of a patient, the duties of professionals shift to palliation and end-of-life care which should also respect the same patient's wishes and preferences whenever possible. Recognising this interpretation of best interests, critical care societies currently support the principle that organ donation should be offered as an option in end-of-life care [1-4]. If the patient wished to donate their organs after their death, professionals should facilitate this whenever the circumstances of the patient's death are consistent with organ donation.

\footnotetext{
*Correspondence: bdominguez@mscbs.es

${ }^{3}$ Organización Nacional de Trasplantes, Madrid, Spain

Full author information is available at the end of the article
}

Organ donation most commonly follows death that results from a severe brain injury. This can occur in different areas within a hospital and in various situations. Following full active treatment in an intensive care unit (ICU), patients may evolve to brain death (BD), a scenario consistent with donation after brain death (DBD). Alternatively, when active treatment is no longer considered to be in the best interests of a patient in an ICU, a decision is made to withdraw life-sustaining therapies (WLST), a scenario compatible with controlled donation after circulatory death (CDCD). A decision to withdraw-or withhold-intensive care measures because of a perceived ominous prognosis in patients with DBI can also take place outside the ICU, either early after hospital admission in the emergency department (ED) or in a hospital ward. The introduction of pathways for patients with a DBI can improve prognostic accuracy and end-of-life care practices for these patients, as well as increase donation opportunities in this third scenario $[5,6]$. There are variations between countries in the frequency of these three circumstances of death (Fig. 1), probably because of different professional practices that are influenced by cultural, religious and social factors [7]. These variations in practice mean that different regions and countries may adopt different strategies in an attempt to increase their deceased donation rates.

Expanding the potential for both DBD and cDCD requires consensus on the determination of death by neurological and circulatory criteria incorporated into national guidance and increasing professional confidence and public acceptance of posthumous donation. DBD is the most common and preferred donation pathway. Nevertheless, high-quality management of severe brain injury is an essential prerequisite for both DBD and CDCD. Proper intensive care management not only increases the potential for patient recovery but also maintains donation potential when prompt identification of patients

\section{Springer}




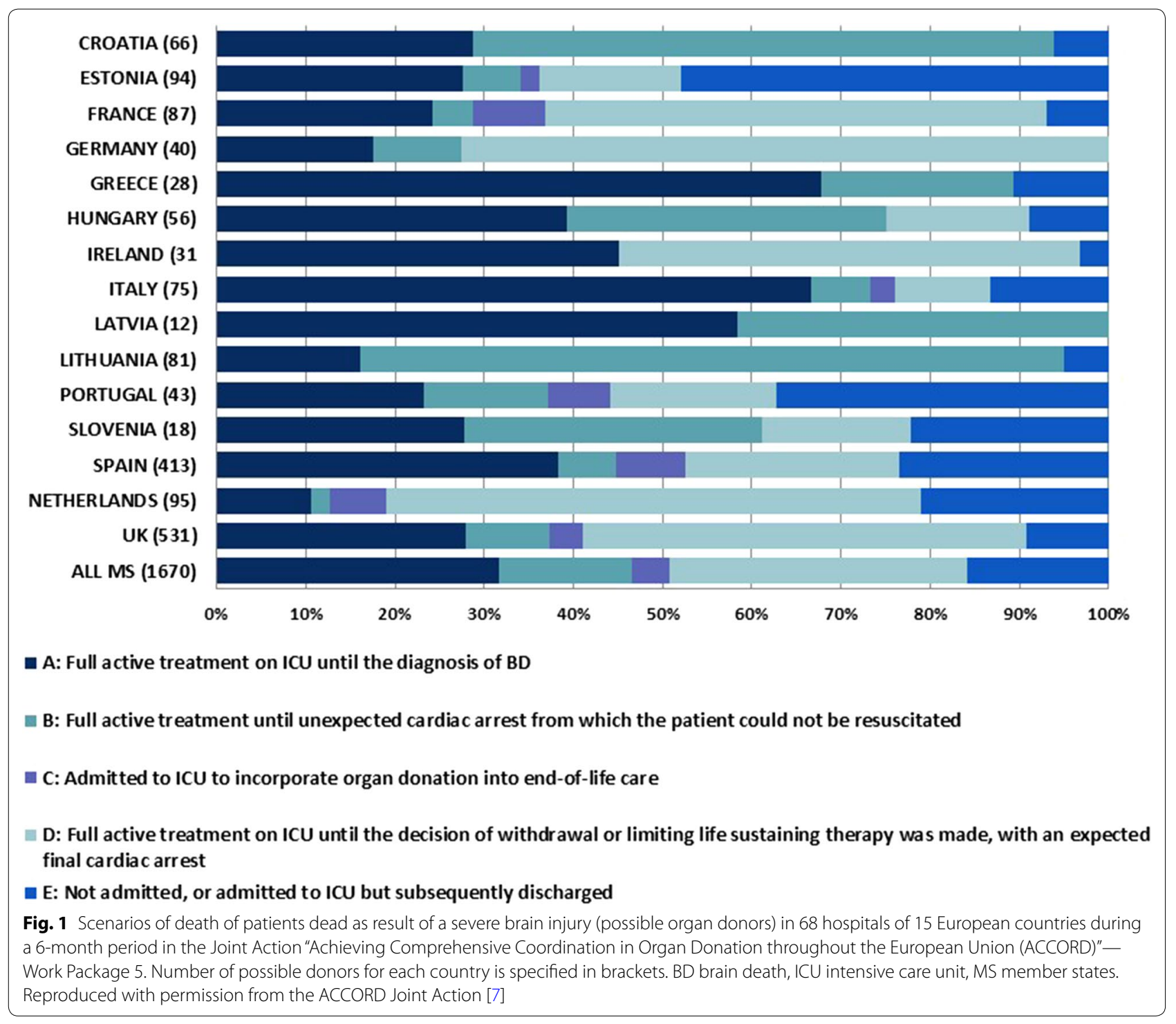

deteriorating to $\mathrm{BD}$ is followed by implementation of effective physiological support. After a decision is made to WLST because active treatment is no longer in the best interests of patients who do not meet $\mathrm{BD}$ criteriaand are unlikely to evolve to BD-then $\mathrm{CDCD}$ should be considered. The option of DBD and CDCD should be incorporated into guidelines for severe brain injury management removing any perception of conflict of interests by intensivists.

Whenever appropriate, BD should be declared and decisions to WLST made in accordance with national guidance, increasing public understanding and awareness that $\mathrm{BD}$ determination and decisions to WLST are made to reduce the burden of ongoing futile treatment and irrespective of any consideration or possibility of organ donation. Acceptance of this as medical best practice at the end-of-life may possibly decrease the number of family refusals to donation, a major issue in several countries.

An early decision to WLST in patients admitted to the ED with DBI, who are perceived at the time of admission to have a condition incompatible with survival or an acceptable functional outcome, is common in some countries. Recent guidance from professional bodies recommend delaying the WLST and admitting the patient to ICU primarily to allow a period of close clinical observation to improve the accuracy of prognostication, and better end-of-life care planning and delivery $[5,6]$. These pathways may lead to an increase in organ donation as a secondary outcome, much as the introduction of post cardiac arrest pathways have done $[8,9]$. The delay in the 
WLST can also lead to up to $30 \%$ of patients who were being considered for $\mathrm{CDCD}$ at this early stage to progress to BD and allow DBD [10].

The decision to withhold intensive care measures in patients being managed outside the ICU because they are not deemed clinically beneficial is also consistent with organ donation. The concept of intensive care to facilitate organ donation (ICOD) has been recently coined to refer to the initiation of life-sustaining therapies in patients with a DBI in whom the decision has been made not to apply any medical or surgical intervention on the grounds of futility, with the intention of incorporating organ donation into their end-of-life care plans [11-13]. ICOD may entail elective non-therapeutic ventilation, haemodynamic support and admission to the ICU to enable the neurological determination of death and DBD. Assessment of prognosis and of the likelihood that BD will occur shortly, appropriate communication with families and use of scarce ICU resources are some of the challenges associated with this practice. ICOD is a reality in several countries [7], and now accounts for more than $20 \%$ of deceased organ donors in Spain [12].

Deceased donation is also possible from persons who die following unsuccessful resuscitation from an in-hospital or out-of-hospital cardiac arrest. Uncontrolled DCD (uDCD) has the potential to significantly increase the donor pool [14] and is a practice supported by the 2015 European Resuscitation Council's guidelines [2]. However, $\mathrm{UDCD}$ remains unusual with the largest programs having been developed in Spain and France [15]. The most important obstacles to the expansion of this type of donation are the absence of a legal framework supporting these programs, ethical concerns, lack of organizational capability and technical expertise, and doubts about the quality of organs retrieved from uDCD donors with an increased risk of primary non function.

In summary, opportunities to increase the donor pool exist in each of the scenarios mentioned above and can be adopted universally if the specific legal, ethical, professional and organizational considerations of every scenario are addressed in each country. Above all, what is needed is the continued engagement of the intensive and emergency care communities and an understanding of physicians' responsibility to attempt to meet the transplantation needs of their citizens, by ensuring that their patients are always given the opportunity to donate their organs after their death when this is a possibility.

\footnotetext{
Author details

${ }^{1}$ The Intensive Care Unit, Southmead Hospital, North Bristol NHS Trust, Bristol, UK. ${ }^{2}$ The National Technical Transplant Council, Italian Health Institute, Rome,
} Italy. ${ }^{3}$ Organización Nacional de Trasplantes, Madrid, Spain.

Compliance with ethical standards

\section{Conflicts of interest}

Alexander Manara is Regional Clinical Lead for Organ Donation for the South West of England. Beatriz Domínguez-Gil is Director General of the Organización Nacional de Trasplantes of Spain. The authors have no other conflict of interests to declare.

Ethical approval

An approval by an ethics committee was not applicable.

\section{Publisher's Note}

Springer Nature remains neutral with regard to jurisdictional claims in published maps and institutional affiliations.

Received: 20 November 2018 Accepted: 23 January 2019

Published online: 6 February 2019

\section{References}

1. Truog RD, Campbell ML, Curtis JR, Haas CE, Luce JM, Rubenfeld GD, Rushton CH, Kaufman DC, American Academy of Critical Care Medicine (2008) Recommendations for end-of-life care in the intensive care unit: a consensus statement by the American College of Critical Care Medicine. Crit Care Med 36(3):953-963

2. Bossaert LL, Perkins GD, Askitopoulou H, Raffay VI, Greif R, Haywood KL, Mentzelopoulos SD, Nolan JP, Van de Voorde P, Xanthos TT, Ethics of Resuscitation and End-of-Life Decisions Section Collaborators (2015) European Resuscitation Council guidelines for resuscitation 2015: Section 11. The ethics of resuscitation and end-of-life decisions. Resuscitation 95:302-311

3. Hernández-Tejedor A, Peñuelas O, Sirgo-Rodríguez G, Llompart-Pou JA, Palencia Herrejón E, Estella A, Fuset Cabanes MP, Alcalá-Llorente MA, Ramírez Galleymore P, Obón Azuara B, Lorente Balanza JA, Vaquerizo Alonso C, Ballesteros Sanz MA, García García M, Caballero López J, Socias Mir A, Serrano Lázaro A, Pérez Villares JM, Herrera-Gutiérrez ME (2017) Recommendations of the Working Groups from the Spanish Society of Intensive and Critical Care Medicine and Coronary Units (SEMICYUC) for the management of adult critically ill patients. Med Intensiva 41(5):285-305

4. Zavalkoff S, Shemie SD, Grimshaw JM, Chassé M, Squires JE, Linklater S, Appleby A, Hartell D, Lalani J, Lotherington K, Knoll G, Potential Organ Donation Identification and System Accountability (PODISA) Conference Participants (2018) Potential organ donor identification and system accountability: expert guidance from a Canadian consensus conference. Can J Anaesth. https://doi.org/10.1007/s12630-018-1252-6

5. Souter MJ, Blissitt PA, Blosser S, Bonomo J, Greer D, Jichici D, Mahanes D, Marcolini EG, Miller C, Sangha K, Yeager S (2015) Recommendations for the critical care management of devastating brain injury: prognostication, psychosocial, and ethical management. A position statement for healthcare professionals from the Neurocritical Care Society. Neurocrit Care 23:4-13

6. Harvey D, Butler J, Groves J, Manara A, Menon DK, Thomas E, Wilson M (2018) Management of perceived devastating brain injury after hospital admission-a consensus statement from stakeholder professional organisations. Br J Anaesth 120:138-145

7. ACCORD Joint Action (2015) Work Package 5-Increasing the collaboration between donor transplant coordinators and intensive care professionals. Final report. http://www.accord-ja.eu/sites/default/files/downl oad_documents/ACCORD_WP_5_ICU_\%26_DTC_Collaboration_FINAL _REPORT.pdf. Accessed Nov 2018

8. Cheethama OV, Thomas MJC, Hadfield J, O'Higgins F, Mitchell C, Rooney KD (2016) Rates of organ donation in a UK tertiary cardiac arrest centre following out-of-hospital cardiac arrest. Resuscitation 101:41-43

9. Manara AR, Menon DK (2017) Withdrawal of treatment after devastating brain injury: post-cardiac arrest pathways lead in best practice. Anaesthesia 72:1179-1184

10. Broderick AR, Manara A, Bramhall S, Cartmill M, Gardiner D, Neuberger $J$ (2016) A donation after circulatory death program has the potential 
to increase the number of donors after brain death. Crit Care Med 44(2):352-359

11. Melville A, Kolt G, Anderson D, Mitropoulos J, Pilcher D (2017) Admission to intensive care for palliative care or potential organ donation: demographics, circumstances, outcomes, and resource use. Crit Care Med 45(10):e1050-e1059

12. Domínguez-Gil B, Coll E, Elizalde J, Herrero JE, Pont T, Quindós B, Marcelo B, Bodí MA, Martínez A, Nebra A, Guerrero F, Manciño JM, Galán J, Lebrón M, Miñambres E, Matesanz R, ACCORD-Spain Study Group (2017) Expanding the donor pool through intensive care to facilitate organ donation: results of a Spanish Multicenter Study. Transplantation 101(8):e265-e272

13. Martín-Delgado MC, Martínez-Soba F, Masnou N, Pérez-Villares JM, Pont T, Sánchez-Carretero MJ, Velasco J, De la Calle B, Escudero D, Estébanez B, Coll E, Pérez-Blanco A, Perojo MD, Uruñuela D, Domínguez-Gil B (2019) Summary of Spanish recommendations on intensive care to facilitate organ donation. Am J Transplant. https://doi.org/10.1111/ajt.15253
14. Grasner JT, Lefering R, Koster RW, Masterson S, Böttiger BW, Herlitz J, Wnent J, Tjelmeland IB, Ortiz FR, Maurer H, Baubin M, Mols P, Hadžibegović I, loannides M, Škulec R, Wissenberg M, Salo A, Hubert H, Nikolaou NI, Lóczi G, Svavarsdóttir H, Semeraro F, Wright PJ, Clarens C, Pijls R, Cebula G, Correia VG, Cimpoesu D, Raffay V, Trenkler S, Markota A, Strömsöe A, Burkart R, Perkins GD, Bossaert LL, EuReCa ONE Collaborators (2016) EuReCa ONE-27 Nations, ONE Europe, ONE Registry: a prospective one month analysis of out-of-hospital cardiac arrest outcomes in 27 countries in Europe. Resuscitation 105:188-195

15. Domínguez-Gil B, Duranteau J, Mateos A, Núñez JR, Cheisson G, Corral E, De Jongh W, Del Río F, Valero R, Coll E, Thuong M, Akhtar MZ, Matesanz R (2016) Uncontrolled donation after circulatory death: European practices and recommendations for the development and optimization of an effective programme. Transpl Int 29(8):842-859 